\title{
El diaconado femenino en la época bizantina*
}

\author{
The feminine deaconship in bizantine period
}

\author{
Mihaela Manescu**
}

\begin{abstract}
RESUMEN ABSTRACT
La aparición del cristianismo cambió radicalmente el status de la mujer: de ser una persona sumisa y sin derechos pasó a ser un ser humano más respetado. Este

artículo se centra en el papel de las mujeres en los primeros tiempos de la historia de la Iglesia, y estudia su implicación en diferentes aspectos: como acompañantes de Jesús y de los apóstoles, su apoyo a la evangelización, la aparición del orden de las viudas, las diaconisas y las vírgenes consagradas. Enfoca con especial interés la institución

de las diaconisas, sus funciones y su papel a lo largo de los siglos hasta que se produjo su desaparición por causas diversas, entre las que se encuentra la romanización de la liturgia con una fuerte

With Christianity the status of women changed radically: from being submissive and without rights they became more respected human beings. This article discusses the role of women at the beginning of the history of Church, and studies their implication in different ways: from the company of the Jesus and the apostles, their support to the evangelization, the apparition of the order of the widows, deaconesses and consecrated virgins. It focuses on the institution of women deacon, their functions and roles along centuries, until it disappears due to different causes, one of which was the Romanization of liturgy with a strong masculine hierarchy.
\end{abstract} jerarquía masculina.

\section{PALABRAS CLAVE}

Mujer, Iglesia, diaconisa, Edad Media, Bizancio

\section{KEY WORDS}

Women, Church, deaconess, Middle Ages, Byzantium

* Fecha de recepción del artículo: 2009-01-08. Fecha de admisión del artículo: 2009-02-12.

** Licenciada en Teología Pastoral (Especialidad Teología Histórica) por la Universidad de Bucarest (Rumanía) y en Medicina por la Universidad Corol Davilla de Bucarest (Rumanía). Estudiante de Tercer Ciclo en la Facultad de Filosofía y Letras en la Universidad de Alcalá. C.e.: mihaelamanescu@yahoo.com 
Justiniano I comenta en la Novella $3.1^{1}$ que Hagia Sophia, la principal catedral de Constantinopla, contaba entre sus servidores con sesenta sacerdotes, diez diáconos y cuarenta diaconisas ${ }^{2}$. Este es simplemente un ejemplo de los muchos registros conservados de la existencia de las diaconisas, cuya institución floreció principalmente en Grecia, Asia Menor, Dalmacia, Siria y Palestina ${ }^{3}$, desde el siglo II hasta el X.

La correspondencia crisostómica dirigida a Olimpiada, una de las diaconisas que formaban parte del clero de la Gran Iglesia de Constantinopla, guarda, además del carácter moral-exegético y documental, las huellas de una emocionante amistad y de un intenso afecto entre los dos servidores de la Iglesia, San Juan Crisóstomo y la diaconisa Olimpiada ${ }^{4}$.

La existencia de las diaconisas en el Imperio Romano de Oriente nos lleva a plantearnos varias preguntas: ¿por qué hubo diaconisas y no sacerdotisas?, ¿qué papel se le asignó a la mujer en la Iglesia?, ¿qué impedimentos se le pusieron para no acceder a la jerarquía de la Iglesia? En este artículo vamos a intentar dar respuesta a estas preguntas, a través de un análisis de la institución del diaconado, en la que las mujeres estuvieron presentes.

Varios han sido los trabajos que, a lo largo del tiempo, han tocado el tema de la función ministerial femenina; entre ellos habría que resaltar las obras de Thierry Maertens, La promotion de la femme dans la Bible et ses applications au mariage et au ministère, Henry Leclercq, Diaconesse, Veuve, y Heinrich Denzinger con los trabajos Deacon's ordination y Deaconess's ordination, sin hablar de los documentos de la época apostólica y patrística que vienen mencionados en las referencias a pie de pagina.

\section{LA INTERVENCIÓN DE LAS MUJERES EN LOS PRIMEROS SIGLOS DE LA IGLESIA}

Desde los comienzos las mujeres tomaron parte activa en los servicios desarrollados por las iglesias, y en el mismo siglo I la mujer se encontraba implicada en la difusión del Evangelio (1 Cor. 11:5) ${ }^{5}$. La naturaleza concreta y las dimensiones exactas de esta función no son fáciles de definir, en parte a causa de los pocos do-

\footnotetext{
1 «Codex Justinianus» («The Code of Justinian»), The Columbia Electronic Encyclopedia, sixth Edition, Columbia University Press, 2003.

2 Alberto CARRILLO-CAZARES, El diaconado femenino, Editorial Mensajero, Bilbao, 1971, pág. 113.

3 Alberto CARRILLO-CAZARES, El diaconado femenino, Editorial Mensajero, Bilbao, 1971, págs. 109-110.

4 Sfântul IOAN GURĂ DE AUR, «Scrisori din exil, despre deprimare, suferinţă şi providenţă către Olimpiada şi cei rămaşi credincioşì, traduceri de diac. Ioan I. Ică jr., Editura Deisis, Sibiu, 2003, págs. 135262.

${ }^{5}$ La Sagrada Ecritura, Ediţie jubiliară a Sfântului Sinod, Editura Institutului Biblic şi de Misiune al Bisericii Ortodoxe Române, Bucureşti, 2001, pág. 1302.
} 
cumentos históricos existentes y en parte a causa de la variación de este ministerio a lo largo del tiempo y de la variedad de nombres que recibió6.

Desde el año 57 las mujeres podían pronunciar oraciones o profecías en el ámbito de las comunidades cristianas. El papel de la mujer como profeta es muy bien conocido en la Iglesia Primitiva de Samaria y Corinto, hecho reconocido por el mismo San Pablo (1 Cor. 11:5) ${ }^{7}$. Cuando estaba profetizando o rezando, si la mujer estaba casada, tenía que llevar un velo que le cubriese la cabeza, hábito que no era válido en el caso de las doncellas o vírgenes que ejercían la misma función en el espacio de la asamblea (1 Cor. 11:5 s) ${ }^{8}$. Conociéndose que en el mundo pagano existía un culto extrovertido, lleno de movimientos y de ruido ${ }^{9}$, San Pablo recomendaba una conducta opuesta, de manera que los asistentes a la Liturgia, y sobre todo las mujeres, se quedasen meditativos adoptando una actitud propia de la interioridad cristiana (1 Cor. 14: 34-35) ${ }^{10}$.

Durante las reuniones todos estaban sentados, y cada uno tomaba la palabra cuando se sentía inspirado para hacerlo ${ }^{11}$. El que recibía la iluminación del Espíritu Santo se ponía de pie y pronunciaba, bajo la influencia del don divino, diversas composiciones de carácter religioso ${ }^{12}$.

Leyendo atentamente la Didajé, se observa que entre maestros y apóstoles estaba bien delimitado el rol de los profetas, y que en ese papel las mujeres estaban colocadas en el mismo plano que los hombres ${ }^{13}$.

La posibilidad de la mujer de exponer sus ideas, profecías o reflexiones se había extendido en las comunidades eclesiásticas post-apostólicas del siglo III, especialmente después de producirse la asimilación del culto y la Iglesia cristianos por la cultura romana del imperio ${ }^{14}$.

Este «servicio de la palabra», en el que la mujer comienza a tomar parte activa, se desarrolla sobre todo en el marco más constante de la vida humana, es decir, en el hogar. Como todas las casas particulares eran sitios donde se celebraba el culto cristiano, se realizó una apertura y un cuadro propicios para el desarrollo de

6 Thierry MAERTENS, La promotion de la femme dans la Bible et ses applications au mariage et au ministère, Tournai 1967, pág. 183-184.

7 La Sagrada Ecritura, Ediţie jubiliară a Sfântului Sinod, Editura Institutului Biblic şi de Misiune al Bisericii Ortodoxe Române, Bucureşti, 2001, pág. 1302.

8 La Sagrada Ecritura, Ediţie jubiliară a Sfântului Sinod, Editura Institutului Biblic şi de Misiune al Bisericii Ortodoxe Române, Bucureşti, 2001, pág. 1302.

9 F.J. BASURCO, El canto cristiano en la Tradición Primitiva, Marova, Madrid, 1968, págs. 118-136.

10 La Sagrada Ecritura, Ediţie jubiliară a Sfântului Sinod, Editura Institutului Biblic şi de Misiune al Bisericii Ortodoxe Române, Bucureşti, 2001, pág. 1307.

11 H. LECLERCQ, «Diaconesse, Veuve», Dictionnaire d'Archéologie Chrétienne et Liturgie, vol III, col. 585.

12 La Sagrada Ecritura, Ediţie jubiliară a Sfântului Sinod, Editura Institutului Biblic şi de Misiune al Bisericii Ortodoxe Române, Bucureşti, 2001, 1 Cor. 14: 33. Leclercq, H., «Diaconesse, Veuve», Dictionnaire d'Archéologie Chrétienne et Liturgie, col. 725 y ss.

13 Didascalia et Constitutiones Apostolorum, Editura F.X.Funk, Paderborn, 1903.

14 Alberto CARRILLO-CAZARES, El diaconado femenino, Editorial Mensajero, Bilbao, 1971, pág. 69. 
los servicios femeninos alrededor de la vida litúrgica en estas iglesias o asambleas: acogida agradable, hospitalidad, cuidado de la mesa donde tenía lugar tanto la Santa Eucaristía como también la comida de después del acto ${ }^{15}$.

El Santo Apóstol Pablo reservaba el nombre de «madres» o «protectoras» (Romanos 16: $2-13)^{16}$ para ciertas cristianas que hacían grandes servicios a los creyentes y recomendaba también que los obispos o diáconos fuesen esposos de una sola mujer, y que tuviera buen entendimiento con su esposa, para que la vivienda de ellos fuese digna de un lugar cristiano (1 Timoteo 3: 2-12) ${ }^{17}$.

De estas colaboradoras del clero masculino se fundaría la orden de las viudas, «jerai» (1 Timoteo. 5: 1-16) ${ }^{18}$, mujeres dedicadas de modo especial al servicio religioso. Entre las virtudes que San Pablo exigía en la mujer para que ocupase un lugar en el ministerio es el probado espíritu de servicio, «que haya lavado los pies a sus hermanos» (1 Timoteo. 5: 1-10) ${ }^{19}$.

Se trata, tal y como nos aparece en la carta dirigida a Timoteo, de una verdadera institución donde mujeres cristianas, respetadas por su edad y vida sin mancha, en familia, desarrollaban un papel especial en el servicio eclesiástico. Partiendo del principio del amor al prójimo que cualquier cristiano tenía que mostrar, ellas asumieron el papel de «comunidad servidora» hacia los miembros desfavorecidos de la comunidad: los enfermos, los pobres y los niños ${ }^{20}$.

Después del siglo III, la orden de las viudas no pudo evitar escaparse del proceso de sacralización, abriendo las puertas a las doncellas. Con el tiempo, se perdió el carácter inicial de la orden, el de acción pastoral, para convertirse en uno sagrado, el de las vírgenes, mucho más preocupadas por el ascetismo, las cosas santas, la castidad y el comedimiento ${ }^{21}$. En la época de transición por la que se ve que pasa la orden de las viudas, comienza a aparecer la orden de las diaconisas, aunque una y otra institución, la de las viudas y la de las diaconisas, tuvieran una identidad original ${ }^{22}$.

De un servicio nacido del entusiasmo de la fe, reglamentado por ciertas normas y prestado por mujeres que sentían la fuerza y el deseo de obsequiar de inmediato a Cristo, en el siglo III, y por primera vez en Siria, la labor de las mujeres se transformó en una institución anclada en el derecho eclesiástico, la de las diaconisas. En esta región, donde circulaba la «Didascalia...», el impulso hacia la creación de las diaconisas brotaba también de la misma presión social. Los hombres

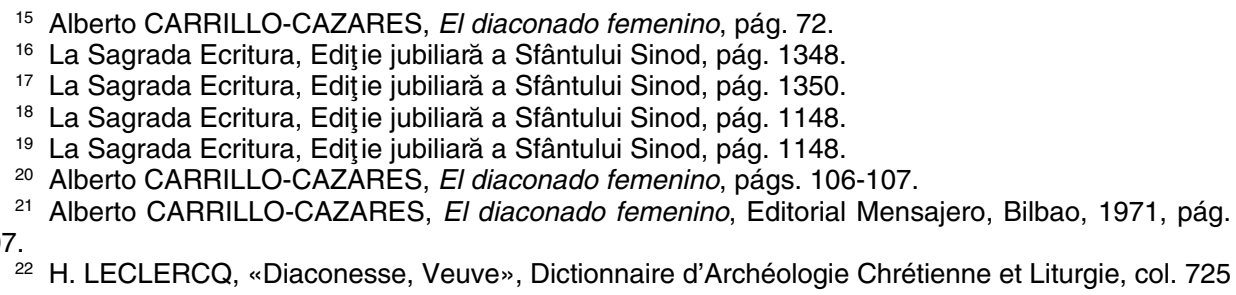


no podían presentarse en las casas de las mujeres para asistirlas; había, además, que guardar la modestia en el bautismo, que se hacia por inmersión y estando desnudos los bautizados.

Desde el siglo III, y al menos hasta el siglo VIII, la Iglesia contó con mujeres diaconisas muy activas y nombradas según normas válidas. Probablemente las diaconisas fueron conocidas ya en la época de los Apóstoles. Por lo menos así se deduciría de un párrafo de la primera Carta a Timoteo del Santo Apóstol Pablo:

«Los diáconos tienen que ser dignos...Inicialmente serán sometidos a tentaciones y luego, si hubieran sido dignos, serán consagrados. Igual, las mujeres tenían que ser impecables en el comportamiento, que no calumnien, que sean sobrias y fieles en todo. Que los diáconos solo se casen una vez» (1 Timoteo 3, 8-12) ${ }^{23}$.

La evolución del servicio de diaconisa apenas se puede reconstruir. A Febe, el apóstol Pablo la encomienda llevar su carta a los Romanos y presentarla a esa Iglesia que no había fundado él y a la que, aunque le era desconocida, quería conocer. Eligiendo a Febe, la presenta a los romanos en calidad de hermana suya $o$ de diaconisa (Rom 16, 1) ${ }^{24}$, recomendándola al mismo tiempo por las palabras: «ella fue la protectora de muchos inclusive mía» $\left(\right.$ Rom 16, 2) ${ }^{25}$. Febe pertenecía seguramente a una orden cristiana. El término de diaconisa usado más arriba no hace referencia a ese orden jerárquico de diácono bien definido y percibido por nosotros hoy día. Ella, por los cargos que cumplía como diaconisa, tenía cierta autoridad, dado que San Pablo mismo invita a sus discípulos de Roma a «que se pongan a su disposición» (Rom 16, 2) ${ }^{26}$. Parece que Febe era también una inteligente mujer de negocios, teniendo en la ciudad de Roma su propio negocio, del que se ocupaba personalmente. Se conoce que, además de los servicios estrictamente religiosos que cumplía, se preocupaba y ayudaba a pobres y enfermos de la ciudad con sus propios medios financieros.

Hacia finales del siglo III, la Iglesia se podía apoyar en grupos de diaconisas, representadas por vírgenes o mujeres casadas. Las viudas podían también cumplir las funciones de las diaconisas. Así, pues, eran recibidas en el orden de las diaconisas de la Iglesia Primitiva tanto viudas o mujeres casadas como jóvenes no casadas, para que más tarde, a la mujer casada aceptada en este orden se la pidiese comedimiento y abstinencia, igual que se les imponía a los hombres que iban a ser nombrados como sacerdotes ${ }^{27}$. Desde finales del siglo IV, a las diaconisas se

\footnotetext{
${ }^{23}$ La Sagrada Ecritura, Ediţie jubiliară a Sfântului Sinod, Editura Institutului Biblic şi de Misiune al Bisericii Ortodoxe Române, Bucureşti, 2001, pág. 1348.

${ }^{24}$ La Sagrada Ecritura, Ediţie jubiliară a Sfântului Sinod, Editura Institutului Biblic şi de Misiune al Bisericii Ortodoxe Române, Bucureşti, 2001, pág. 1291.

${ }^{25}$ La Sagrada Ecritura, Ediţie jubiliară a Sfântului Sinod, Editura Institutului Biblic şi de Misiune al Bisericii Ortodoxe Române, Bucureşti, 2001, pág. 1291.

${ }^{26}$ La Sagrada Ecritura, Ediţie jubiliară a Sfântului Sinod, Editura Institutului Biblic şi de Misiune al Bisericii Ortodoxe Române, Bucureşti, 2001, pág. 1291.

${ }_{27}$ Alberto CARRILLO-CAZARES, El diaconado femenino, Editorial Mensajero, Bilbao, 1971, pág. 107.
} 
les conferirían Órdenes paralelas a las Órdenes del diácono. Sin embargo, la diaconisa es excluida de los servicios específicos del diácono, a quien no puede hacer competencia. Además, no puede formar parte de la jerarquía eclesiástica en ninguno de los tres grados: obispo, presbítero y diácono ${ }^{28}$.

\section{LOS CARGOS DE LAS MUJERES DIACONISAS}

Las obligaciones de las diaconisas, aunque diferían en función de la comunidad eclesiástica u obispado al que pertenecían, eran principalmente actividades de beneficencia y caridad, de cuidado de los pobres, de preparación de las catecúmenas pendientes de ser bautizadas, y de vigilancia de las viudas y, en ciertas regiones, de las vírgenes. Entre sus atribuciones entraban también la mediación de las conversaciones entre el obispo de la zona y los grupos de mujeres y la orientación espiritual de las mujeres que vivían en ámbito pagano, de los adolescentes $y$ de los niños.

Además, ellas también se encargaban de las siguientes tareas: constatación de la integridad corporal, embalsamamiento de los fallecidos, mediación de los diálogos entre las mujeres cristianas y los dirigentes de la comunidad, asistencia a las reuniones particulares de los obispos, sacerdotes y diáconos con las mujeres cristianas $^{29}$.

\subsection{La asistencia en el bautizo de las mujeres}

Las diaconisas ayudaban al obispo en el bautizo de las mujeres ${ }^{30}$. La escritura «Estatuta Ecclesiae Antiquae» guarda una costumbre en la que se dice:

«Las viudas o las monjas que se eligen para la preparación de las mujeres que tienen necesidad de bautizarse, tienen que ser instruidas para que puedan enseñar también a las mujeres del espacio rural y sin educación, usando palabras claras y con sentido, entendibles... así las mujeres pueden responder a las preguntas del que las bautiza, en el momento del bautizo; además, se enterarán de cómo vivirían después de que hubieran recibido el bautizo... ${ }^{31}$.

Cuando se escribían estos Estatuta..., en Occidente habían dejado de existir las diaconisas y «las viudas o monjas», mientras que en los documentos orientales se hablaba del cargo específico de la diaconisa.

El sacerdote hacía la primera unción de la catecúmena sobre la frente y la diaconisa terminaba de ungir todo el cuerpo. Después, ayudaban a las recién bauti-

${ }^{28}$ Las Constituciones Apostólicas, II, 28.

29 Las Constituciones Apostólicas, II, 26.

30 Didascalia et Constitutiones Apostolorum, Editura F.X.Funk, III. 16. 1-2 şi 4, Paderborn, 1903.

${ }_{31}$ Catholic Encyclopedia, Heinrich Joseph Dominicus Denzinger, 10th edition, Freiburg, 1908, edición preparada por Clemens Bannwart, cap 100. 
zadas a entrar en la piscina, las recibían cuando salían del agua, tal como los diáconos recibían a los hombres y, luego, las hacían comparecer vestidas en ropa de bautizo, para ser confirmadas por el obispo.

La diaconisa ayudaba a las catecúmenas a bajar las escaleras de oeste a este, para que de ese modo la mujer que se dejaba hundir en el agua mirase hacia Oriente. El propósito de que «ningún hombre viera alguna catecúmena desnuda» ${ }^{32}$, y el deseo de que la administración del bautizo se realizase «con adecuada decencia» ${ }^{33}$, motivó que la diaconisa se encargase tanto de la unción como de la sumersión de la catecúmena. Mientras la diaconisa cumplía con su función, un hombre invocaba el Nombre de la Santa Trinidad en el agua.

Según un antiguo ritual copto de Egipto, el desarrollo del evento hubiera sido el siguiente:

«La persona que iba a ser bautizada se desnudaba... se le recogían los ornamentos de plata y oro y la ropa... Se ungía a la persona sobre los senos, sobre los brazos, sobre el vientre, sobre la espalda, sobre la mitad de ambas manos.... ${ }^{34}$.

\subsection{La responsabilidad de las mujeres en la asamblea de la Iglesia}

La responsabilidad de las diaconisas en la asamblea de la Iglesia consistía en encargarse de la entrada y de la colocación de las mujeres en el lugar acondicionado especialmente para ellas ${ }^{35}$. Era deber de las diaconisas participar, junto a los diáconos, en la aceptación o no de los extranjeros durante las celebraciones religiosas $^{36}$. Esto cabe deducir de la siguiente frase acerca de la vigilancia de la entrada:

"Cuando tu, Obispo, convocas una reunión de la Iglesia, eres como un comandante de un gran buque, asegúrate que los encuentros se hagan con mucha atención... los diáconos son como los marinos que preparan el sitio con mucho cuidado y compostura para sus hermanos que son como si los pasajeros... así, las diaconisas se quedan a la entrada para mujeres como si estuvieran en un barco... $y$, si alguien no se encontrase en su sitio, entonces que sea amonestado por el diácono... además, se vigila la entrada para que no entrasen los infieles o los que no están iniciados ${ }^{37}$.

La diaconisa, que, después del diácono, tenía un papel importante en lo que concierne a la organización, asumía en general la entera responsabilidad sobre las

32 Las Constituciones Apostólicas, 3, 15.

33 Las Constituciones Apostólicas, 3, 16.

34 H. DENZINGER, «Deacon's ordination» (págs. 229-233) y «Deaconess's ordination» (págs. 261262), en Ritus Orientalium, Würzburg, 1864.

35 Didascalia et Constitutiones Apostolorum, Editura F.X.Funk, Paderborn, 1903.

36 Las Constituciones Apostólicas, 2, 58.

37 Las Constituciones Apostólicas, 2, 57. 
mujeres $^{38}$. Vigilaban la admisión de las mujeres desconocidas en la comunidad eclesiástica a la que pertenecían, de la misma manera que los diáconos controlaban a los hombres que se iban a convertir al cristianismo ${ }^{39}$. También velaban por la preservación del orden entre las mujeres halladas en la iglesia y, además, tenían responsabilidad pastoral sobre éstas ${ }^{40}$.

\subsection{El apostolado de la diaconisa en la comunidad cristiana}

Un privilegio especial otorgado y reservado a las diaconisas era la lectura pastoral y la liturgia destinada a las mujeres cristianas enfermas. En este servicio se incluía la visita, el consuelo, la caricia, la pronunciación de la palabra de Dios hacia la enferma, la liturgia por la posición de las manos sobre la cabeza de las mujeres y la unción del cuerpo de las enfermas. Cuando las personas estaban postradas en su lecho, las diaconisas tenían la autoridad de llevarles la Santa Eucaristía. La diaconisa se repartía con el diácono el cuidado de los enfermos y la vigilancia de las personas de la parroquia que tenían diversos tipos de problemas ${ }^{41}$.

Una responsabilidad especial de las diaconisas era la de cuidar de las «viudas", que en aquella época hacía referencia a una clase de mujeres de edad, que recibían una ayuda económica y sostenimiento por parte de la comunidad y que prestaban ciertos trabajos para la Iglesia ${ }^{42}$.

Las diaconisas, además, tenían que enseñar el Evangelio a los hombres y a las mujeres en sus propias casas. Este ha sido uno de los motivos originales para que las mujeres se implicasen en el apostolado, tal como escribe San Clemente de Alejandría:

«...dado que los apóstoles, obsequiados sin descanso al proceso de Evangelización, según la estipulación de su estatuto, cogían con ellos mujeres no como esposas sino como hermanas para repartir esta responsabilidad...ellas se dirigían a las mujeres que habitaban en sus casas personales, y de ese modo, a través de ellas, la enseñanza cristiana llegaba a las viviendas que acogían mujeres, sin levantar sospecha alguna» ${ }^{43}$.

\subsection{La función ministerial de la mujer}

Aunque las mujeres diaconisas no asistían al Obispo en el altar del mismo modo que los diáconos, tenían, no obstante, acceso a éste bajo diferentes for-

38 Las Constituciones Apostólicas, 3, 19 y 2, 26.

39 Las Constituciones Apostólicas, 3, 19.

40 Didascalia et Constitutiones Apostolorum, Editura F.X.Funk, Paderborn, 1903.

41 Didascalia de los Apóstoles, 13, 1-7.

42 Las Constituciones Apostólicas, 3,7.

${ }^{43}$ Sfântul CLEMENT AL ALEXANDRIEI, «Stromatele» în «Scrieri», partea a II - a, traducere de Pr. D. Fecioru, Colecţia Părinţi şi Scriitori Bisericeşti, volumul 5, Editura Institutului Biblic şi de Misiune al Bisericii Ortodoxe Române, Bucureşti, 1982, cartea 3, capitolul 6, \& 53, pág. 210. 
mas ${ }^{44}$. De manera particular, podían recoger los Sacramentos del altar para dar de comulgar a las mujeres que no se podían desplazar ${ }^{45}$. También, según las leyes de la Iglesia de Siria, las mujeres diaconisas ayudaban en el altar cuando no había diáconos hombres, y daban la comunión a los enfermos ${ }^{46}$. Documentos de la Iglesia de Siria indican que «con la autorización del Obispo, las diaconisas pueden verter el vino y el agua en el cáliz» ${ }^{47}$, es decir, ejercer la misma función del diácono en el altar.

En los monasterios, la abadesa diaconisa, en ausencia del sacerdote o del diácono, tenía derecho a subir al bema o tarima ${ }^{48}$, allá donde se encontraba el sitio de lectura, a incensar tanto los libros santos como a las hermanas presentes, y a leer el Evangelio.

Según refiere Giacomo di Edesa en las Risoluzioni Canoniche ${ }^{49}$, las diaconisas podían dar la Santa Comunión a las mujeres si vivían en un espacio monacal. Esta costumbre era reconocida aún en la Edad Media, cuando las abadesas, que habían heredado ciertos derechos de las diaconisas, distribuían la Comunión y leían el Evangelio en la iglesia.

En las Iglesias Nestoriana y Monofisita, en las comunidades en las que faltaba la presencia del sacerdote o del diácono, la diaconisa parece que tenía el derecho, en aquella época de oro del diaconado femenino, de dar la comunión tanto a las mujeres como a los niños ${ }^{50}$.

Además de los textos previos ya comentados, aportamos dos más para entender mejor la posición de los diáconos, tanto hombres como mujeres, en el esqueleto de la Iglesia. En la Didascalia de los Apóstoles, se afirma que:

«Il. 26. 5. El diácono es aquí imagen del Cristo, así que sea amado por vosotros. 6. La Diaconisa sea honrada de vosotros como imagen del Espíritu Santo. 7. Y los presbíteros que sean respetados como si fueran imagen de los apóstoles.... ${ }^{51}$.

Las obligaciones de las diaconisas aparecen en las Constituciones Apostólicas:

44 Didascalia et Constitutiones Apostolorum, Editura F.X.Funk, Paderborn, 1903. Catholic Encyclopedia, Heinrich Joseph Dominicus Denzinger, 10th edition, Freiburg, 1908, prepared by Clemens Bannwart.

${ }^{45}$ Las Constituciones Apostólicas, III, 8.

${ }^{46}$ Alberto CARRILLO-CAZARES, El diaconado femenino, Editorial Mensajero, Bilbao, 1971, pág. 109.

47 Lamy, A., « De Syrorum Fide et Disciplina», Giovanni Telo, Risoluzioni Canoniche, § 38, Louvain, 1859, págs. 89-91.

48 Alberto CARRILLO-CAZARES, El diaconado femenino, Editorial Mensajero, Bilbao, 1971, pág. 109.

49 A. LAMY, «De Syrorum Fide et Disciplina», Giovanni Telo, Risoluzioni Canoniche, § 24, Louvain, 1859, págs. 89-91.

50 Alberto CARRILLO-CAZARES, El diaconado femenino, Editorial Mensajero, Bilbao, 1971, pág. 109-111.

51 Didascalia de los Apóstoles, 26, 5-7. 
«VIII. 28. 4. El diácono no consagra, no da la euloguia (los sacramentos), pero la recibe del obispo y del presbítero, desde siempre bautiza, no ofrece la Eucaristía, pero cuando el obispo o el presbítero la traen (la Eucaristía) la da al pueblo, pero no como presbítero sino como sirviendo a los sacerdotes. 5 . A ningún otro clérigo le es permitido que haga el trabajo del diácono. 6. La diaconisa no bendice y no hace nada de lo que hacen los presbíteros y los diáconos, solo vigila las entradas y ayuda a los sacerdotes en el bautizo de las mujeres...») $)^{52}$.

\section{EL ESTATUTO DE LA MUJER DIACONISA EN EL MARCO ECLESIÁSTICO}

A lo largo del tiempo, el tema del diaconado femenino fue analizado en el ámbito de los concilios ecuménicos ${ }^{53}$, y se estipularon diversos criterios en relación con la edad y el estatuto de las mujeres diaconisas ${ }^{54}$.

La edad a la que una mujer podía recibir esa alta investidura era en un principio, hacia el año 390, a los 60 años. El sínodo ecuménico de Calcedonia las aceptó incluso a partir de los 40 años, igual que los concilios de Zaragoza (381) y de Agda (506). Esta edad era la estipulada también en el edicto de Mayoriano. El sínodo de Cartagena, del 419, las admitía desde los 25 años, e incluso antes si hubiera motivo urgente ${ }^{55}$.

El Sínodo Trulano ${ }^{56}$, convocado en Constantinopla en el año 692, volvía a afirmar la edad mínima establecida en el Sínodo de Calcedonia ${ }^{57}$. Comentamos que el nombrado sínodo habla de una auténtica misa de bendición (cheirotonia) en el caso de las diaconisas, usando exactamente el mismo término que en el caso de la bendición de los diáconos de sexo masculino. El teólogo ortodoxo Evangelos Theodorou subrayaba que el uso del vocablo técnico cheirotonia en los documentos de aquel sínodo tiene una significación muy señalada ${ }^{58}$.

El segundo Sínodo Ecuménico de Nicea, de 787, aprueba y confirma, asimismo, los cánones apostólicos, las resoluciones de los Concilios generales y locales anteriores a éste, como señal de conformidad con la realidad espiritual de aquel

52 Las Constituciones Apostólicas, 28, 4-6.

53 Prof. Dr. Arhim. Ioan FLOCA, Canoanele Bisericii Ortodoxe, Editura Institutului Biblic şi de Misiune al Bisericii Ortodoxe Române, Bucureşti, 1992. Conciliorum oecumenicorum decreta, editura AlberigoDossetti, Bologna, 1973.

54 Conciliorum oecumenicorum decreta, editura Alberigo-Dossetti, Bologna, 1973.

55 Prof. Dr. Arhim. Ioan FLOCA, Canoanele Bisericii Ortodoxe, Editura Institutului Biblic şi de Misiune al Bisericii Ortodoxe Române, Bucureşti, 1992. Conciliorum oecumenicorum decreta, editura AlberigoDossetti, Bologna canon 16, pág. 249.

56 Prof. Dr. Arhim. Ioan FLOCA, Canoanele Bisericii Ortodoxe, Editura Institutului Biblic şi de Misiune al Bisericii Ortodoxe Române, Bucureşti, 1992. Conciliorum oecumenicorum decreta, editura AlberigoDossetti, Bologna canon 14, pág. 113-114.

57 Prof. Dr. Arhim. Ioan FLOCA, Canoanele Bisericii Ortodoxe, Editura Institutului Biblic şi de Misiune al Bisericii Ortodoxe Române, Bucureşti, 1992. Conciliorum oecumenicorum decreta, editura AlberigoDossetti, Bologna canon 15, pág. 86.

58 Evangelos THEODOROU, «E 'cheirotonia' e 'cheirothesia' ton diakonisson», în revista Theologia, nr. 25, 1954, págs. 430-469, 576-601; nr. 26, 1956, págs. 57-76. 
momento. Esto significaba que las disposiciones referentes a las diaconisas eran también reafirmadas.

En el marco de la Iglesia Primitiva, hasta el Concilio de Nicea estas mujeres que participaban en el ministerio divino no formaban un clero aparte, separado y santificado, sino que se consideraba que formaban parte de los laicos ${ }^{59}$. Tan sólo después de finales del recordado concilio ecuménico, sobre finales del siglo IV, cambia esta situación y desde aquel momento las diaconisas reciben las órdenes y las dignidades que hasta entonces sólo correspondían a los diáconos ${ }^{60}$.

En todas las iglesias que tenían diaconisas en sus jerarquías, desde el punto de vista litúrgico, el lugar de éstas venía después del de los diáconos, tanto en la recepción de la Santa Eucaristía como en la ordenación.

\section{LA ORDENACIÓN DE LAS DIACONISAS}

En los primeros siglos, la ordenación de las mujeres diaconisas en las diócesis de lengua griega y siríaca era una verdadera tradición sacramental, equivalente a la que se desarrollaba en el caso de los diáconos hombres.

El texto auténtico del ritual de la ordenación de las mujeres se ha conservado gracias a unos manuscritos de gran valor que describen el extenso ritual de la ordenación. Hacemos referencia a un manuscrito griego/bizantino encontrado en el Codex Barberinus Graecus 336, del siglo VIII, de la Biblioteca del Vaticano ${ }^{61}$. EI texto griego se publicó definitivamente en el año 2000, en Roma, por Stefano Parenti y Elena Velkovska.

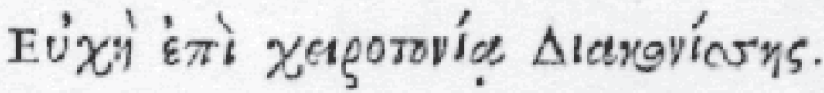

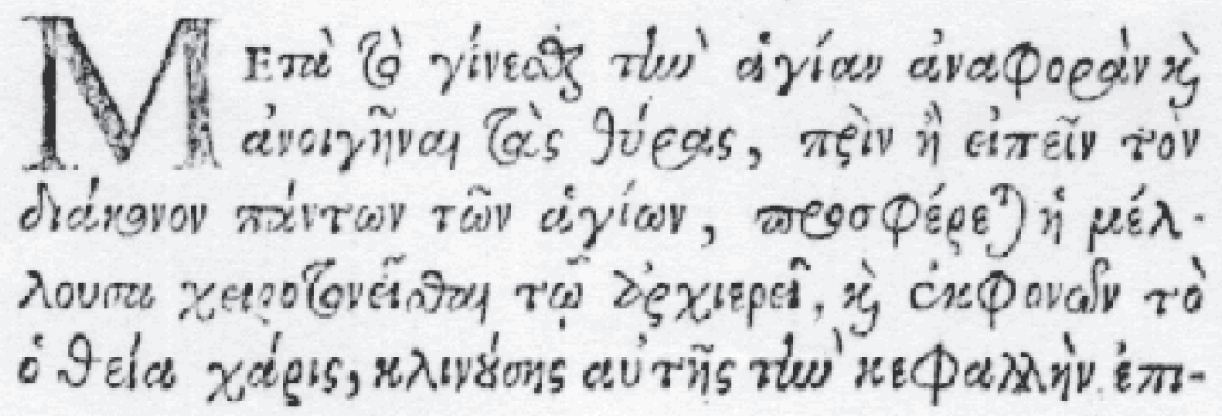

59 Alberto CARRILLO-CAZARES, El diaconado femenino, Editorial Mensajero, Bilbao, 1971, pág. 109-111.

60 Michael SCHMAUS, «Teoologia dogmatica», tomo VI, pag 685.

61 Stefano PARENTI, Elena VELKOVSKA, «L'Eucologio Barberini Gr. 336»- Biblioteca «Ephemerides Liturgicae Subsidia» numărul 80, Edizioni Liturgiche, Roma, 2000, págs. 170-174 şi 336-339. 
n'ต

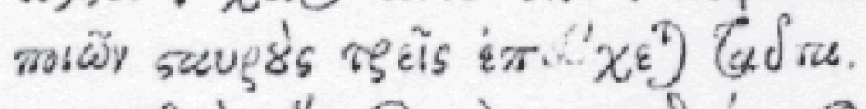

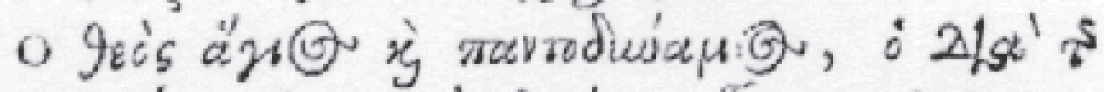

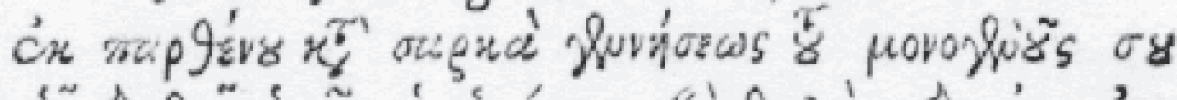

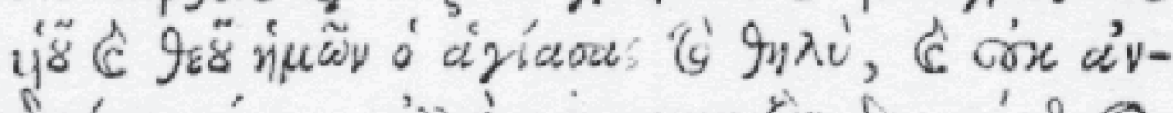

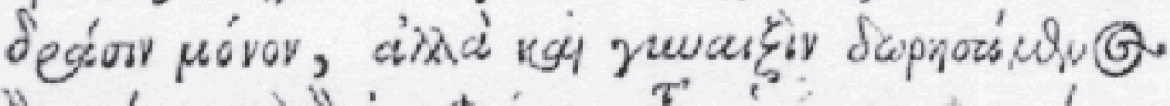

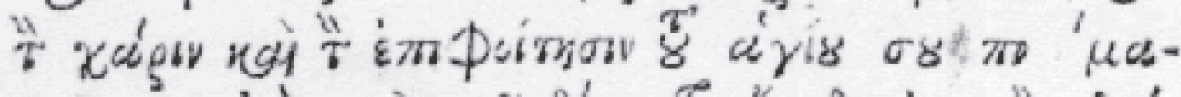

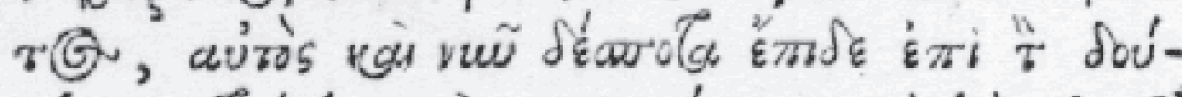

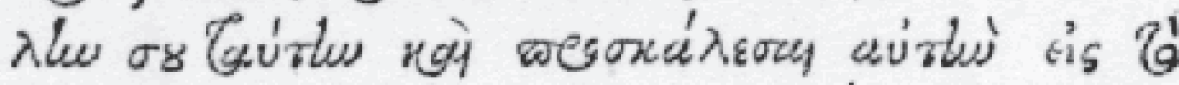

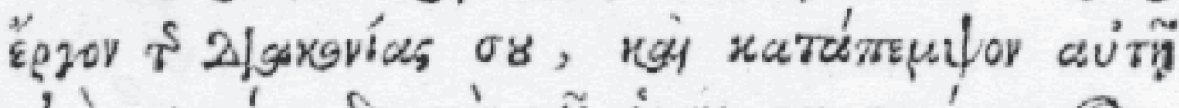

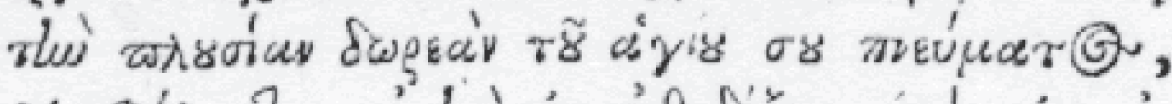

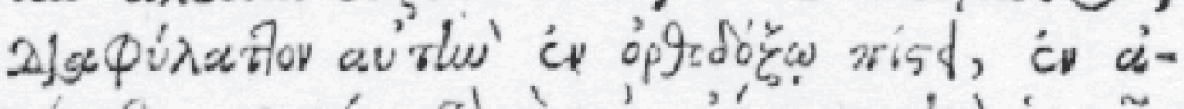

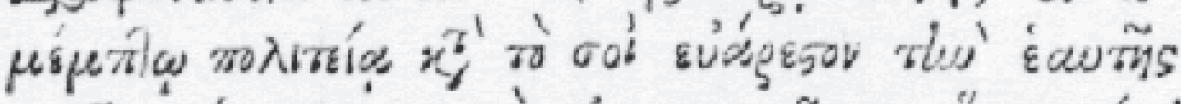

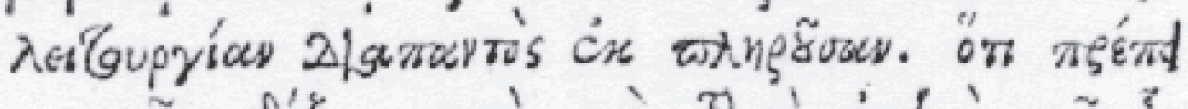

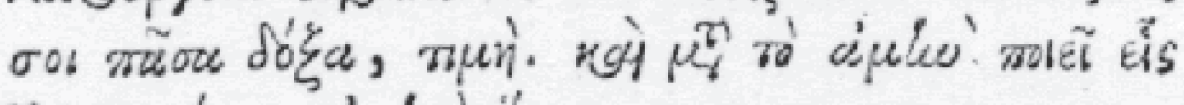

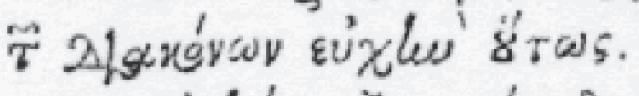

Figura 1. Parte de la inscripción del manuscrito del Codex Barberini.

Otro testimonio sobre la institución y existencia del diaconado femenino lo tenemos en un fragmento de Las Constituciones Apostólicas, de fines del siglo IV:

«Hacia diaconisa, yo, Bartolomé el Apóstol, ordeno lo siguiente: 2. Obispo, imponga tus manos sobre ella estando presentes los presbíteros, los diáconos y las diaconisas y digas así: Dios Todo Poderoso, Padre de Nuestro Señor Jesús Cristo, el creador del hombre y de la mujer, El que llenó de Espíritu Santo a Miriam (Iş 15, 20), a Dobra (Jd 4, 4), a Ana (1 Rg $1 \mathrm{sq}$ ) y a Hulda (4 Rg 22, 14), que no consideraste indigno que Tu Hijo naciese de una mujer, El que tanto en la tienda de la confesión como en el templo elegiste mujeres como vigilantes de Tus santas Puertas, 2. Tu Mismo busca hacia esta sierva tuya, que fue elegida (procheirizomene) para diaconía y la bendiga a ella con Espíritu Santo y la limpies de toda suciedad tanto del cuerpo como del alma $(2$ Co 7,1$)$, para que cumpla con dignidad y diligencia la labor encargada en Tu gloria y alabanza... Amén» ${ }^{62}$.

62 Las Constituciones Apostólicas, VIII 19.1-20.1. 
Evangelos Theodorou, en el artículo titulado « $E$ 'cheirotonia' e 'cheirothesia' ton diakonisson", publicado en la revista Theologia, num. 25, de $1954^{63}$, realiza un análisis sobre el fenómeno de la ordenación y encuentra algunas diferencias entre el ritual de ordenación del diácono y el de la diaconisa, que, comenta el autor, en realidad no cambian la esencia del acto.

Según algunos rituales ${ }^{64}$, el diácono, cuando se acerca al altar, lo toca con la frente y se arrodilla al momento. En cambio, la mujer permanecerá de pie durante su ordenación. El diácono recibe el Cáliz Santo y los signos de su nuevo ministerio, mientras que la diaconisa no (según otras fuentes sí). Ambos reciben la Comunión en el altar, después de que el diácono haya distribuido la Sangre y el Cuerpo del Cristo a los presentes (por lo que se conoce hasta ahora, la mujer no lo podía hacer, salvo en situaciones especiales, como es el caso de las mujeres enfermas). Al parecer, las diferencias radicaban en las distintas funciones que cada uno tenía y en la posibilidad de que ella se encontrara durante el periodo menstrual.

\section{DOCUMENTACIÓN DE REFERENCIA SOBRE DIACONISAS}

Ayudados por la correspondencia de los sacerdotes, conocemos a muchas diaconisas por sus nombres: Salvina, a quien le escribía San Jerónimo ${ }^{65}$ y que habría servido como diaconisa en Constantinopla; Macrina, la hermana de San Basilio el Grande, y su amiga, diaconisa Lampadia66; Anastasia, una de las asistentas del Obispo Severo de Antioquia ${ }^{67}$.

En documentos históricos aparece también una diaconisa anónima ${ }^{68}$, de la que sabemos que sirvió en Antioquia durante las persecuciones del emperador Juliano el Apostata (361-363 d.C.). Así lo narra el historiador Teodoro de Ciro (466), quien comenta que aquella diaconisa instruyó y convirtió a la religión cristiana al hijo de un ministro pagano. Después de haber preparado al joven para el bautizo, la diaconisa lo ayudó a escapar de la casa de su padre para que pudiera reunirse con la comunidad cristiana de una localidad más segura ${ }^{69}$.

63 Evangelos THEODOROU, «E 'cheirotonia' e 'cheirothesia' ton diakonisson», în revista Theologia, nr. 25, 1954, págs. 430-469, 576-601; nr. 26, 1956, págs. 57-76.

64 Jacob GOAR, «Euchologion sive Rituale Graecorum», Paris, 1647, págs. 262-264 şi 264-267. Codex Syriacus Vaticanus, no 19.

65 JEROME, Select Wrmediaitings and Letters, vol. V, «Letters and Select Works» vol VI, series II, în Nicene and Post - Nicene Fathers Christian Library, translated by Rev. S. Thelwall, T\&T Clark, Edinburgh, 1870.

66 PALADIU, Istoria Lausiaca (Lavsaikon) - scurte biografii de pustnici, Editura Institutului Biblic şi de Misiune al Bisericii Ortodoxe Române, Bucureşti, 1994.

67 John WIJINGAARDS, The Tablet, the 8 of May, 1999, pág. 623-624.

68 Kristin ARNT, Die Diakonissen der armenischen Kirche in kanonischer Sicht, Viena, 1990.

69 Anne JENSEN, Gottes selbstbewusste Töchter: Frauenemanzipazion im frühen Christentum, Freiburg 1992, págs. 49-50. 
Asimismo se menciona tanto a la diaconisa Theosebia ${ }^{70}$, la esposa de San Gregorio de Nyssa, como a Procula y Pentadia ${ }^{71}$, dos diaconisas a las que San Juan Crisóstomo enviaba cartas. A estas añadimos también otros miles de mujeres que sirvieron, pero cuyos nombres quedarían desconocidos, igual que tantos sacerdotes y diáconos.

Olimpiada ${ }^{72}$ (el personaje principal de la obra crisostómica Letters to Olimpiada) es un personaje que destaca por el hecho de que, en el tránsito del siglo IV al $\mathrm{V}$, en pleno periodo patrístico, algunos de los Santos Padres le dirigen diversas escrituras o cartas, además de la correspondencia crisostómica mencionada al comienzo. Gregorio Nacianceno ${ }^{73}$ le envía un poema el día de su boda, y Gregorio de Nyssa le dedica su famoso comentario en forma de homilías a la obra «El Cantar de los Cantares ${ }^{74}$. Además, Paladio le dedicaría, por un lado la totalidad del capítulo XVII de su Diálogo ${ }^{75}$, y, por otro lado, más de veinte años después, el capítulo 56 de la Historia Lausiaca ${ }^{76}$ —en la que ella nos aparece presentada junto a famosos ascetas egipcios.

El nombre de algunas diaconisas se conservó también gracias a las inscripciones de las tumbas en las que fueron colocadas después de morir. Fueron identificadas al menos veintiocho. Como ejemplo podemos dar el de Sofía de Jerusalén (siglo IV) ${ }^{77}$, cuya inscripción griega dice: «Aquí (descansa) yace la sierva y la siempre virgen para Cristo, la Diaconisa, la segunda Febe [Rom 16,1], que murió en paz el día 21 de Marzo". Otras diaconisas mencionadas en inscripciones son: Teodora de Gaul (siglo VI) ${ }^{78}$, Atanasia de Delphi (siglo V) ${ }^{79}$, diaconisa Éneo de Jerusalén ${ }^{80}$. Muy expresiva es la imagen de Bitalia, que aparece pintada en un nicho de la Catacumba de San Genaro de Nápoles. Exhibe vestidura roja, sostiene la Palabra de Dios y parece que se encuentra durante un ritual delante de un tipo de altar. La pintura podría datar del siglo $\mathrm{V}$, y puede que sea una de aquellas que enfadaban al Papa Gelasio. Una inscripción fúnebre identifica a la mujer de la que hablábamos: «Bitalia descansa en paz» ${ }^{81}$. En la misma catacumba existe también otra pintura interesante: tres mujeres de aspecto alegórico construyen una iglesia simbólica con ladrillos y alguna otra masa ${ }^{82}$. Parece que estas funciones sacerdo-

70 Ute EISEN, Ämtsträgerinnen im frühen Christentum, Göttingen, 1996.

71 Ute EISEN, Ämtsträgerinnen im frühen Christentum, Göttingen, 1996.

72 Sfântul IOAN GURĂ DE AUR, Scrisori din exil, despre deprimarepágs. 135-262.

73 Parainetikon pros Olympiada, PG 37, 1542-1551.

74 PG 44, 755 sq. Traducere si comentarii de pr. prof. D.Staniloaie, PSB 29,Bucuresti, 1982, págs. 113-124.

75 PALADIO, PG, 47, 61.

76 PALADIU, Istoria Lausiaca (Lavsaikon) - scurte biografii de pustnici, Editura Institutului Biblic şi de Misiune al Bisericii Ortodoxe Române, București, 1994.

77 Revue biblique, New 1 (1904) págs. 260-262.

${ }_{78}$ Leclercq, H., Dictionnaire d'Archéologie Chrétienne et Liturgie, Paris, 1921, vol. IV, col. 570-571.

79 Ute EISEN, Ämtsträgerinnen im frühen Christentum, Göttingen, 1996.

80 Maffei, Museum Veronense, Verona, 1749, pág. 179.

81 New Women, New Church, vol. 15-16, IX, 1992-1993.

82 New Women, New Church, vol. 15-16, IX, 1992-1993, pag. 5. 
tales cumplidas por mujeres en esta región de Italia (menos que en otras zonas del Occidente) se desarrollaron debido al contacto entre ésta y las regiones griega y bizantina, donde la diaconía femenina tenía una importancia y esparcimiento mayores. Además, estas regiones estaban influidas por las corrientes gnósticas y montanistas de Oriente y Asia Menor, donde se ordenaban mujeres incluso para los cargos de presbítero y obispo a lo largo del siglo II, prácticas condenadas por la Iglesia en diversos sínodos y concilios ecuménicos.

\section{LA EVOLUCION DEL DIACONADO FEMENINO Y LA CONDICIÓN DE LA MUJER EN RELACIÓN CON LOS PREJUICIOS ECLESIÁSTICOS}

El diaconado femenino conoció una fuerte oposición en las regiones de lengua latina, como Italia, el Norte de África, Galia y Britania. En Occidente, el diaconado femenino continuó existiendo hasta comienzos de la Edad Media, bajo la forma de algunas «bendiciones» que se daban a las abadesas. Era tan sólo una sombra del fenómeno, si lo ponemos en comparación con la realidad de Oriente.

En los primeros siglos la mujer había desarrollado un papel importante en el ámbito eclesiástico, estrenándose, de alguna manera, en actividades fuera de su hogar (las diaconisas, las viudas). Conocemos que la sociedad romana no permitía a la mujer asumir funciones ni responsabilidades públicas. De forma progresiva, del entorno social y jurídico, esta idea se trasladó al mundo eclesiástico. Así que, el acceso de la mujer al servicio divino le fue negado.

El por qué la actividad iniciada en la Iglesia Primitiva no tuvo continuidad, se podría explicar a través del triple prejuicio al que estuvo sujeta la mujer ${ }^{83}$ : ser humano «incompleto» (según la filosofía griega y las leyes romanas), portadora del pecado original (el Espíritu Santo no se podía transmitir a través de una persona pecadora) y sin pureza durante el periodo menstrual. Por el contrario, los testimonios apostólicos (Las Constituciones Apostólicas, Didascalia de los Apóstoles) consideraban que las mujeres que menstruaban no necesitaban procesos ni ritos de purificación y que no tenían por qué quedarse fuera del espacio eclesiástico en este periodo ${ }^{84}$.

No es un fenómeno aparecido de forma esporádica, explícitamente en tan sólo un momento, sino que se mantuvo a lo largo de la historia. Partiendo de aquí, los teólogos consideraron que a un ser tan impuro como era considerada la mujer no se le podía confiar el cuidado de los Sacramentos de Cristo. Comenzó con Tertuliano (155-245), que declaraba que los mismos vínculos matrimoniales le-

83 Sfânta Scriptură, Ediţie jubiliară a Sfântului Sinod, Editura Institutului Biblic şi de Misiune al Bisericii Ortodoxe Române, Bucureşti, 2001. Catholic Encyclopedia, Heinrich Joseph Dominicus Denzinger, 10th edition, Freiburg, 1908, prepared by Clemens Bannwart.

84 Didascalia et Constitutiones Apostolorum, Editura F.X.Funk, Paderborn, 1903. 
gales estaban manchados por el deseo carnal o concupiscencia ${ }^{85}$. San Jerónimo (347-416) continuó esta línea en su forma de pensar, mostrando que había alteración en cualquier forma de relación intima, incluso en los matrimonios legítimos ${ }^{86}$.

La romanización tan perfecta de la liturgia trajo consigo una estructura jerárquica fuertemente masculinizada. Con el tiempo, la exuberancia y el vigor de la Iglesia Primitiva disminuyeron paulatinamente y se llegó a perder el aporte femenino a la vida litúrgica.

La muy comentada idea de la sacralización realizó un cambio mayor, cuyas consecuencias no se podían ver fácilmente a comienzos del siglo IV. A los clérigos, cualquiera que fuera su rango en la jerarquía eclesiástica, al principio no se les prohibió el matrimonio, y el otorgamiento de los órdenes santos continuó ofreciéndose también a los casados. Poco a poco, se impondrá la limitación del matrimonio para los miembros eclesiásticos, para que pudiesen estar limpios ante los Sacramentos y el santuario.

Si observásemos el fenómeno descrito arriba, se podría ver que de la abstinencia por voluntad propia en ciertos momentos se llegaría a la prohibición del matrimonio para cualquier clérigo perteneciente a los órdenes superiores. En el siglo XII los Concilios I y II de Letrán establecieron la nulidad del matrimonio que cualquier clérigo perteneciente a los órdenes superiores pudiera contraer. Esta exclusión del matrimonio, tildado de forma consciente o inconsciente de impuro, al igual que la negación de la convivencia acompañada de abstinencia del sacerdote con la mujer legítima, representa el inicio y la base del alejamiento total de la mujer de todas las funciones religiosas ${ }^{87}$.

La desaparición de la mujer del escenario litúrgico puede que sea debida también al horror de los convertidos romanos frente a toda clase de música, bailes y mujeres con mala fama, coristas o cantantes, a las que los apenas convertidos de la religión pagana las asociaban a las orgías que se celebraban con ocasión de las fiestas religiosas paganas.

Al desaparecer el orden del diaconado femenino quedarían sólo algunas de sus funciones: por una parte, serían aceptadas con título honorífico las esposas de los diáconos, y, por otra parte, se confundiría con las monjas, con las mujeres que formaban parte de la comitiva papal o con las abadesas. En algunas regiones quedaría como título honorífico otorgado a alguna viuda o mujer muy religiosa, pero sin que se mantuviera ya nada de los servicios cumplidos antes por las mujeres ordenadas.

85 TERTULIAN, The Writings of Tertullian, vol. III, IV, în Ante - Nicene Fathers Christian Library, translated by Rev. S. Thelwall, T\&T Clark, Edinburgh, 1870. De cultu feminarum», libro 1, cap. 1.

${ }^{86}$ JEROME, Select Writings and Letters, vol. V, «Letters and Select Works» vol VI, series II, în Nicene and Post - Nicene Fathers Christian Library, translated by Rev. S. Thelwall, T\&T Clark, Edinburgh, 1870, Letter 71 to Lucinius», c. 3, Letter 22 to Eustochius», c. 37, Adv. Iovin. I, 20.

87 Jean Paul AUDET, Mariage et celibat dans le service Pastoral de l'Eglise. Éditions de l'Orante, Paris, 1967 , pág. 72 . 


\section{CONCLUSIÓN}

La diaconisa representaba un orden femenino, muy singular, que se formó a lo largo de una de las épocas más gloriosas de la vida pastoral y litúrgica de la Iglesia. La aparición, el desarrollo y el decaimiento del diaconado femenino es, sin embargo, una historia complicada.

El privilegio concedido a la mujer al ser aceptada en el orden de las diaconisas, por imposición de las manos del obispo y con la bendición de éste, demuestra que existía un orden específico religioso y pastoral, que superaba la habitual actividad religiosa de cualquier cristiano. Sin embargo, varios factores impiden definir con claridad la situación: los documentos son muy pobres, el vocabulario cristiano primitivo era aún bastante impreciso y las atribuciones del entorno eclesiástico intercambiables. A pesar de todo, se pueden vislumbrar algunos aspectos interesantes.

Desde el siglo IV, poco tiempo después de que el emperador Constantino otorgase libertad de culto a los cristianos, la mujer sería excluida, gradualmente, del entorno eclesiástico, paralizándose de este modo aquel desarrollo progresivo de la responsabilidad y participación de la mujer en el servicio divino.

En el siglo IV, el diaconado femenino estaba muy bien definido, teniendo estatuto jurídico y litúrgico propio. Lo que al comienzo era la expresión del cariño y de la dedicación de unas mujeres generosas que ofrecían sus servicios a las iglesias durante el día y durante la noche, llega a constituirse en una institución que iba a gozar de mucho esplendor, poco conocido por las mujeres deseosas de oficiar hoy en día.

Mientras algunas formas de espiritualidad cristiana femenina, como el monacato, se instituyeron también durante la época bizantina y continúan hasta hoy, otras, como la analizada en este artículo, dejaron de funcionar por motivaciones diversas: el abandono del bautizo de los adultos, la institución del orden de vírgenes dedicadas a la vida monástica, la institucionalización y romanización de la Iglesia autorizada por Constantino el Grande. Los cargos que la diaconisa desarrollaba en el servicio litúrgico se suprimieron bruscamente, debido al proceso complicado que la Iglesia sufrió durante su evolución. Poco a poco se apagaron las dos instituciones, muy activas en los primeros siglos: la de las viudas y la de las diaconisas, mientras la institución de las vírgenes se iba desarrollando. Las mujeres ni podían dar la bendición, ni participar en el bautizo de las mujeres o en la unción de los enfermos. Además, se les prohibió que entrasen en ciertos lugares del santuario, que tocasen los Sacramentos o que cumpliesen cualquier empleo litúrgico (la lectura de los textos religiosos, cantar las oraciones).

Nos queda todavía camino por delante para ampliar el estudio sobre este tema y dar respuestas acertadas a las preguntas que inicialmente nos hacíamos. Somos nosotros, los de hoy día, quienes debemos trabajar para elucidar el tema y para valorar el renacimiento y la continuidad del diaconado femenino. 